\title{
1 Adaptive significance and long-term survival of asexual
}

\section{2 lineages}

3

$4 \quad$ Lodé Thierry

5 UMR-CNRS 6552 ETHOS, Campus de Beaulieu, Université de Rennes 1, France

6 thierry.lode@univ-rennes1.fr

7

8

9

10 Running title: survival of asexual lineages 


\section{Abstract}

Important questions remain about the long-term survival and adaptive significance of eukaryotic asexual lineages. Numerous papers dealing with sex advantages still continued to compare parthenogenetic populations versus sexual populations arguing that sex demonstrates a better fitness. Because asexual lineages do not possess any recombination mechanisms favoring rapid changes in the face of severe environmental conditions, they should be considered as an evolutionary dead-end.

Nevertheless, reviewing literature dealing with asexual reproduction, it is possible to draw three stimulating conclusions. 1) Asexual reproduction in eukaryotes considerably differs from prokaryotes which experience recombination but neither meiosis nor syngamy. Recombination and meiosis would be a driving force for sexual reproduction. Eukaryotes should therefore be considered as a continuum of sexual organisms that are more or less capable (and sometimes incapable) of sexual reproduction. 2) Rather than revealing ancestral eukaryotic forms, most known lineages of asexual eukaryotes have lost sex due to a genomic conflict affecting their sexual capacity. Thus, it could be argued that hybridization is a major cause of their asexuality. Asexuality may have evolved as a reproductive mechanism reducing conflict within organisms. 3) It could be proposed that, rather than being generalists, parthenogenetic hybrid lineages could be favored when exploiting peculiar restricted ecological niches, following the "frozen niche variation" model. Although hybrid events may result in sex loss, probably caused by genomic conflict, asexual hybrids could display new original adaptive traits, and the rapid colonization of environments through clonal reproduction could favor their long-term survival, leading to evolutionary changes and hybrid speciation. Examination of the evolutionary history of asexual lineages reveals that evolutionary processes act through transitional stages in which even very small temporary benefits may be enough to counter the expected selective disadvantages.

Keywords asexual advantage - frozen niche variation - hybrid - meiotic drive - parthenogenesis - prokaryotes - recombination - Red Queen - scissiparity - sexual conflict - speciation 


\section{Introduction}

Although sexual reproduction is widely spread out among eukaryotes, the maintenance of asexual populations remains a major evolutionary issue. Deleterious mutations are expected to accumulate in asexual lineages and therefore contribute in limiting their long-term persistence (Keightley and Eyre-Walker 2000). Nevertheless, the putative evolutionary advantages of a costly mechanism such as sexual reproduction have been debated for decades (Barton and Charlesworth 1998) and sex is often considered as a late evolutionary acquisition.

Sexual reproduction promotes high genetic variety, whereas clonal reproduction produces identical genomes between descendants. Thus, most of the theories supporting a presumed benefit of sexual strategies have proposed that sexual reproduction enlarges the genetic diversity in the lineages in which natural selection acts (see Bernstein et al. 1984; MaynardSmith 1978; Kondrashov 1994; Rice 2002; Lesbarrères 2012). This benefit would be mainly due to genetic recombination that generates numerous changes in genomes (Kondrashov 1994; Hadany and Feldman 2005). The claimed importance of recombination has even led many authors to consider as identical sex and genetic recombination (Otto 2009). The recombination of genes is indeed shared in both eukaryotic and prokaryotic phyla, suggesting both an ancient origin and a common function. As a result, sex can be considered as a nearly universal mechanism because of the ubiquity of gene recombination in living species, and genetic recombination could have been imposed as a mechanism for diversifying through evolutionary history.

Nevertheless, the mechanisms of sexual reproduction are not confined only to recombination. Recombination is only fragmentary in bacteria and archaea and all prokaryotes ignore the mechanisms of reductional meiosis and of syngamy (Vos 2009), essential characteristics of sexual eukaryotes. Recombination is a chemical process rooted in DNA exchange, while sex 
appears as a biological process (Penny 1985; Cavalier-Smith 2002). Thus, sex can be defined as an evolutionary mechanism that combines a total recombination of genomes, the development of meiosis, gametogenesis and a process of cell fusion called syngamy. This operational definition restricts sex to eukaryotes (Normark et al. 2003). Consequently, sex in eukaryotes significantly differs from the bacterial recombination (Redfield 2001; Lodé 2012a).

The three basic characteristics of sexual reproduction are found in almost all eukaryotes, while prokaryotes are chiefly reproduced by binary fission (Lawrence 1999). This fact may suggest both the establishment of a common evolutionary mechanism in all eukaryotes and an ancient divergence with the other groups of prokaryotes (Lodé 2011, Lodé 2012b). The lack of intermediate organisms in the prokaryote-to-eukaryote transitions could indicate that recombination and sexual reproduction have accelerated the basic divergence. In addition, numerous eukaryotes privileged anisogamy, introducing male and female divergence.

However, some eukaryotes exhibit different reproductive mechanisms, such as parthenogenesis or scissiparity, and some are thought to be as exclusively asexual, though they are rare exceptions. The existence of these asexual organisms raises a crucial question about the evolutionary processes that led to the establishment of sexual reproduction and many of asexual lineages are the subject of experimental studies dealing with the potential benefits of sex (Egel 2000; Agrawal 2009). What can these exceptions tell us about evolutionary processes?

In fact, it is somewhat surprising to consider that so few eukaryotes show asexual reproduction. Although the concept of species in asexual organisms has been questioned (Hillis 2007) since sexual isolation is considered the basic mechanism of speciation (de Queiroz 2005), a large majority of the species practicing partial recombination with neither meiosis nor syngamy are prokaryotes (Vos 2009). Asexual reproduction is observed in protists, in yeast or in plants but 
there are also many examples of animals that have interested researchers (Halkett et al. 2005). Rotifers, for instance, are a group of dioecous animals, but males are unknown in several species so that bdelloid rotifers asexually produce diploid eggs that only develop into females (Birky 2004). In some annelids, mollusks and arthropods, asexual reproduction is often the preferred mode of reproduction. Finally, asexual reproduction also exists in some vertebrates such as fish and lizards for example (Schultz 1971). The diversity of concerned species suggests that those showing asexual reproduction therefore do not have a common evolutionary origin and that their asexuality could be dependent on factors specific to the species' life history.

The possible evolutionary advantages of asexual reproduction have been discussed (see Butlin and Griffiths 1993). For example, the optional parthenogenetic reproduction of aphids is usually associated with severe and changing climatic conditions and seems to be a response to environmental stresses (Suomalainen 1962, 1976). In social hymenoptera, parthenogenetic reproduction is generally limited to the production of males because they are haploid, but there are some cases of female-producing parthenogenesis (Slobodchikoff and Daly 1971; review in Wenseleers and Van Oystaeyen 2011). Reproduction by scissiparity or binary fission is found both in plants, protists, cnidarians and annelids, which however can also have sexual phases. Gynogenesis and hybridogenesis could be considered as forms of parthenogenesis that require sperm to initiate embryogenesis, with no fecundation (gynogenesis) or excluding the paternal genome (hemiclonal hybridogenesis) (Schmidt 1993; Beukeboom and Vrijenhoek 1998; Vorburger 2001; Pagano et al. 2003; Schmeller et al. 2005). Hybridogenetic lineages realize a hemiclonal transmission of genes since they discard one complete genome of either parental species.

Nonetheless, the reason why asexual reproduction can be maintained in such a variety of different groups remains enigmatic. It has been shown that sexual species may suffer a double constraint, called the "two-fold cost of sex" (Maynard-Smith 1978; Williams 1975; Uyenoyama 1984). Asexual lineages avoid both the cost of meiosis and the cost of males (Lively and Lloyd 
124

1990). Therefore, an asexual population has an intrinsic capacity to grow exponentially, the asexual lineage doubling in the population with each generation.

Consequently, from a purely numerical point of view, asexual populations should outcompete sexual species to extinction when they are in a similar ecological situation (Schley et al. 2004). Because of the obvious evolutionary benefits that asexual populations have over sexual species, it is difficult to understand why asexual lineages have not invaded the most stable environments. Referring only to adaptive advantages, it is hard to understand why phasmids have privileged asexual reproduction, including parthenogenesis and hybridogenesis (Passamonti et al. 2004; Ghiselli et al. 2007), while related species, such as dragonflies or mantis, exhibit sexual reproduction.

\section{The Red Queen}

It has been hypothesized that species reproducing asexually might suffer from greater parasite load than sexual species. The "Red Queen model" asserts that sexual recombination could offer an immediate benefit (Hamilton 1980; Hamilton et al. 1990). By mixing genes from different individuals, the resulting diversity of descendants could be an efficient response to pathogen and parasite selection. Sexual reproduction, and especially recombination, may increase the anti-parasite advantage in the sexual lineages, thus the parasite load should be higher in asexual populations (Ladle 1992).

Numerous field studies have supported some of these predictions (Hakoyama et al. 2001; Lively and Jokela 2002; Lively 2009). For instance, it has been found that sexual Poeciliopsis fish species survive a parasite load more successfully than asexual fish populations (Lively et al. 1990; Mateos et al. 2002). Examining the parasite load in Carassius fish living sympatrically, Hakoyama et al. (2001) found that sexual Carassius had a significantly lower load of parasites than asexual populations. Similarly, the parasite loads and juvenile mortality in a parthenogenic freshwater gasteropod Campeloma limum were found to be significantly higher in autodiploid 
152

153

154

155

156

157

158

159

160

161

162

163

164

165

166

167

168

169

170

171

172

173

174

175

176

177

178

179

parthenogens, but the variance of prevalence was also higher in autodiploid parthenogens, suggesting that unparasitized parthenogens have temporarily escaped these virulent parasites (Johnson 2000). A survey of the freshwater ostracod Eucypris virens has also revealed that very few populations support parasite infections (Bruvo et al. 2011). Similarly, a host-parasite model by Howard and Lively (1994) showed the coexistence of sexual and asexual lineages, even under moderate levels of virulence.

By contrast, some clonal species have revealed great adaptive potential. In daphnia, tests have failed to find evidence that parasite load is able of causing synergistic epistasis between mutations in their hosts (Salathé and Ebert 2003; Haag et al. 2003). Tobler and Schlupp (2005), when testing the Red Queen prediction using four populations of the sexual fish species Poecilia latipinna and its asexual relative Poecilia Formosa, detected no differences in parasite load. Indeed, sexual recombination could disrupt favorable gene combinations more often than it generates them. Further, asexual geckos exhibited lower parasite infestations than sexual relatives (Hanley et al. 1995; Brown et al. 1995; Kearney and Shine 2005). Natural hybrids often show very high levels of heterozygosity, thus, it has been hypothesized that asexual vertebrates may have a higher resistance to parasites owing to their hybrid origin (Brown et al. 1995).

Genetic diversity is present in asexual populations through a variety of different clones (Lushai et al. 2003), and asexual groups do not diversify less rapidly than sexual species (Barraclough et al. 2003). For instance, the pattern of diversification found in bdelloid rotifers is suggestive of their adaptive radiation rather than reflecting neutral divergence and genetic drift (Fontaneto et al. 2007). Similarly, in parthenogenetic populations of the oribatid mite, either asexual or sexual lineages may show a comparable rate of speciation (Heethoff et al. 2007).

Analyzing 101 eukaryotic phylogenies, Venditti et al. (2010) concluded that the Red Queen model of a species losing a race in a selective environment should be replaced by a view linking speciation to rare stochastic events. Reviewing plant/pathogen interactions, Clay and Kover 
(1996) also found that gene-for-gene interactions are generally not consistent with the Red

181 Queen hypothesis.

182

183 Finally, in bacteria reproducing asexually, there is no evidence of meiosis, but co-evolution with

184 viruses determines the frequency of mutation rates (Pal et al. 2007). This suggests that the 185 parasite-host co-evolution model (Red Queen) functions as a driver for mutation frequency even 186 when sex is not implicated.

187

188

\section{Benefit of recombination}

190

191

192

193

194

195

Since asexual reproduction results in clonal progeny, it was assumed that this reduced diversity, linked to a lack or an incomplete recombination could reduce the fitness of asexual populations. The absence of recombination in asexual organisms results in accumulation of deleterious mutations, while recombination in sexual populations is known to achieve a "Muller's Ratchet" (Muller 1964; Felsenstein 1974). Furthermore, sexual species would be advantaged because they produce a wide variety of descendants, whereas asexual populations only have a clonal progeny with a reduced ability to adapt to changing environments (Kondrashov 1994; Penny 1985; Kondrashov 1993; de Visser and Elena 2007). Thus, genetic recombination is thought to be an essential mechanism that favors the long-term survival of a species. Further, sexual genomes contain many genes, each containing many strongly epistatic nucleotides (Watson et al. 2011).

The advantage of recombination was assessed in Escherichia coli microbacterial cultures by introducing the F plasmid carrying Rec genes for conjugation (Cooper 2007). All recombining lineages showed greater fitness than non-recombining lineages. In yeast populations, Goddart et al. (2005) found that sexual lineages exhibited the best fitness in selective conditions. Similarly, Morran et al. (2011) showed that co-evolution with a bacterial pathogen (Serratia 
marcescens) resulted in significantly increased outcrossing in mating populations of the nematode Caenorhabditis elegans.

209

210 Nonetheless, asexual organisms occupy larger ranges, survive at higher latitudes and altitudes 211 and have a greater ability to colonize than their sexual relatives (Kearney 2005; Hörandl et al. 212 2008). Furthermore, even bacteria may obtain new genes by direct transfer from other bacteria, 213 promoting their adaptation to a changing environment (Ochman et al. 2005; Pal et al. 2005). 214 McDaniel et al. (2010) found high genetic transfer in marine bacteria which demonstrated the widespread capability of variance and adaptation in bacteria with no sexual practices. Finally, several species with clonal genomes have revealed great adaptive potential (Loxdale and 217 Lushai 2003; Pagano et al. 2008). As a result, it is quite possible to conclude that asexual 218 organisms with no sexual recombination may show a better adaptive potential than expected.

In fact, considerable confusion is still attached to the term "asexual" reproduction. The consequences of sexual reproduction have been tested by comparing a wide variety of sexual species and their "asexual" relatives, which often exhibit very different life-histories. The "asexual" organisms are species in which sexual reproduction has never been observed or species that practice asexual reproduction alternatively or sometimes optionally. Thus, the definition of asexual reproduction is typically based on negative evidence. Numerous species can be considered as obligate sexual but it is difficult to say that there are obligate asexual species. Although they consist in all-females lineages, parthenogenetic species are considered as "asexual" species as well as some organisms showing scissiparity or hemiclonal reproduction. Thus "asexual" reproduction includes situations that greatly contrast. Some species have developed reproduction through scissiparity or binary fission and reconstruction of new organic tissues.

The situation is further complicated because many "asexual" organisms have retained a capacity for sexual reproduction. This is the case in the haploid-diploid hymenoptera or in aphids for instance. In monogonate rotifer species, both reproduction by parthenogenesis and 
sexual reproduction take place during the life cycle (Fontaneto et al. 2007). Therefore, these species are rather facultative sexual species in which reproductive mechanisms differ according to the environmental context. Even species that do not use obvious sexual reproduction may still show some characteristics of sex. Most asexual lineages are dioecus, and, despite a change in syngamy, individuals may have almost normal meiosis but not until complete reductional division (meiosis II) and sometimes may even show a complete meiosis.

If recombination is shared by many prokaryotic organisms, meiosis and syngamy mechanisms are found only in eukaryotes (Vos 2009). It might be thought that, in most cases, "asexual" eukaryotes experienced both a deterioration of meiosis mechanisms and a lack of syngamy.

246 Nonetheless, repeated accumulation of mutations and lack of recombination in an asexual 247 population should result in a "Meselson effect" whereby one organism is affected by high 248 sequence divergence of two different genomes because alleles at a single locus evolve 249 independently of each other (Mark-Welch and Meselson 2000; Butlin 2002). Thus, it remains difficult to identify what benefits asexual lineages can derive from the absence of meiosis and syngamy. In addition, many asexual organisms are phylogenetically related to other sexual species and can live under relatively similar environmental conditions.

\section{Intragenomic conflict and asexual reproduction}

A better comprehension of what asexual organisms are is needed in order to understand the importance of asexual reproduction in evolutionary history. It is often useful to distinguish between the evolutionary forces favoring the origin and the subsequent elaboration and maintenance of a trait. Even very weak advantages can select for the maintenance of sex, if the process is the result of a series of separate events (Lodé 2011).

The sexual cycle of eukaryotes is often supposed to have arisen from the infection of eukaryotic cells by prokaryotic genome parasites (Bell 1993). Based on supposed primitive microbial 
eukaryotes such as protists which have often been assumed to be asexual organisms, it has usually been accepted that the ancestors of all eukaryotes were asexual or, at least, facultatively sexual isogamous organisms (Normark et al. 2003; Ramesh et al. 2005). Nevertheless, most of the support for this alleged primitive asexuality derives from the lack of observing sex or motile organisms considered as males. It could be noticed that anisogamy is not a mandatory requirement for sex, although it is often privileged in sexual organisms. After recombination and meiosis, isogamy should be a probable primitive step for sex. Although there is some evidence suggesting that current asexual organisms originated from ancient asexual organisms (Chaplin et al. 1994; Schön et al. 1998), considerable contradictory evidence suggests that they were originally sexual species (Judson and Normark 1996; Normak et al. 275 2003; Mark-Welch et al. 2004; Matheos and Vrijenhoek 2007). The small number of asexual 276 lineages seems to indicate that asexual eukaryotes are species that have lost sex rather than 277 archaic species that have survived until today. Thus, it might be possible to accept the 278 hypothesis that the ancestor of eukaryotes had certain primitive characteristics of a sexual 279 being, such as recombination and meiosis (Lodé 2011; 2012a). Indeed, most eukaryotic species exhibited sexual reproduction while asexual eukaryotes are not organized in a continuum but are found scattered throughout the tree of life.

In fact, the various forms of asexual reproduction might stem from casual factors affecting some species rather than being the result of a common process. This could lead us to assume that asexual reproduction depends much more on the individual life histories of each species, and could result in peculiar adaptive conditions. The association of such different species in only one category such as "asexual reproduction" may be artificial and does not give a general explanation for the evolutionary process.

"Asexual" eukaryotes mainly reproduce by apomixis, a mechanism in which diploid eggs produced by mitotic division develop parthenogenetically into females. Thus, in eukaryotes, a species is expected to reproduce "asexually" when no functional males are detected. However, recently, male darwinulid ostracods were found although this family was considered as an 
exclusively ancient asexual group (Smith et al. 2006). Reviewing the literature on ciliates, 295 Dunthorn and Katz (2010) concluded that the putative asexuality of this lineage is an observational artifact; so many microbial eukaryotes could actually be secretively sexual.

297 Numerous plants produce asexual seeds but have a sexual male function. Oribatid mites can 298 show a reversal from "obligate" asexual forms to sexual forms (Domes et al. 2007), but sexuality 299 might have been lost repeatedly (Goldberg and Igic 2008). Similarly, evidence for a sexual 300 stage was observed in the supposedly "obligatory" asexual fungi $A$. fumigatus (Dyer and 301 Paoletti 2005) revealing that "asexual" eukaryotes may have something to do with sex.

303 Eukaryotic organisms with "asexual" reproduction clearly show an alteration of the reproductive 304 mechanisms involved in sexual reproduction. Many "asexual" lineages are genetically related to 305 sexual species and mostly possess sexual ancestors. Some worm species reproducing 306 asexually by scissiparity have revealed hybrid origins, and epigamy was their ancestral 307 reproductive state (Lunt 2008; Nygren and Sundberg 2003). Asexual fungal species have 308 sexual ancestors and may also be cryptically sexual (Sun and Heitman 2011). Parthenogenetic 309 species, such as phasmids (Passamonti et al. 2004), Poeciliid fishes (Lamatsch et al. 2007), 310 unisexual Aspidoscelis/Cnemidophorus lizards (Parker and Selander 1976; Crews et al. 1986, 311 Cullum 2000), hybridogenetic water frogs (Vorburger 2001; Pagano et al. 2003; Schmeller et al. 312 2005) and fishes (Schartl et al. 1995; Angers and Schlosser 2007) are believed to use clonal or 313 hemiclonal asexual reproduction, but have sexual ancestors and exhibited numerous traits 314 shared by gonochoristic species (i.e. separate sexes in separate individuals). In Timema stick 315 insects, parthenogens are evolved spontaneously from sexually reproducing species 316 (Schwander and Crespi 2008). Asexual bdelloids are probably allotetraploids resulting from 317 ancient hybridization events. Reconstructions of rotifer phylogenies suggest that sexual 318 reproduction has been lost during their evolutionary history on at least three different occasions 319 (Mark-Welch and Meselson 2000). In Equisetum, female gametophytes became hermaphroditic 320 or males when cultured in the presence of sucrose (Guillon \& Raquin 2002). Finally, some 321 amphibians and many reptiles depend on environmental cues to determine sex and in some 322 fish, this process can persist throughout life, so Crews (2012) argued that most eukaryotic 
lineages evolved from bisexual ancestors that could adopt both male and female roles related to their ovarian cycle (Fig. 1.).

Thus, it could be said that sexual reproduction became "facultative" in eukaryotic organisms showing a decline in sexual fertility or losing sex during their evolutionary history, although they have sexual ancestry.

Asexual organisms may arise by mutation or loss of some key genes (Lattorff et al. 2005), but hybridization events give rise to conflicts of genomes due to a lesser genetic compatibility between the protagonists. Indeed, hybrid sterility or incompatibilities have been a focus in reproductive isolation and speciation, especially since the Haldane rule (1922) states that the sterility of heterogametic sex is the most affected by hybridization. In angiosperms, polyploidy and gene interactions should be a cause of asexual development (Quarin et al. 2001). Parthenogenetic stick insects should have a hybrid origin (Schwander and Crespi 2008). In fact, most unisexual populations have generally originated from hybridation with sexual species (Simon et al. 2003; Wooley et al. 2004; Kearney 2005; Mable 2007; Matheos and Vrijenhoek 2007), thus it could be argued that hybridization is a major cause of asexuality in eukaryotes.

Asexual lineages lost sex after a genomic shock leading to the adoption of a form of endomitosis reproduction, sometimes with a normal meiosis preceded by a replication. Numerous mechanisms may have evolved to reduce conflict within organisms, such as separation between germ and somatic lines, or the uniparental transmission of mitochondria. Calling attention to the role of hybridization in angiosperms, Carman $(1997 ; 2007)$ hypothesized that a heterochrony in the expression of genes involved in reproduction could cause apomeiotic development of the embryo leading to asexual lineages. Hybridization between individuals showing an asynchronous expression of genes could result in a disorder in the stages of development, via epigenetic modification in polyploids. These conflicts of genomes particularly affect meiosis and segregation distortion, some alleles being over-represented in the gametes. Although this possibility has been discussed (Coyne and Orr 1993) meiotic drive is known to 
affect sexual reproduction (Wilkinson and Fry 2001) and to contribute to hybrid sterility (see McDermott and Noor 2010 for a review), and thus is an important mechanism for possible speciation (Presgraves 2007; Phadnis and Orr 2009). Hybrid sterility and reduced fertility probably share common genetic factors. Some polyploid hybrid organisms with a disrupted meiosis can only reproduce "asexually", which emphasizes the importance of genome conflict affecting meiotic sex. Most asexual eukaryotic organisms are parthenogenetic hybrids, and the changes in their reproduction modes could originate in the conflict-related genetic perturbations of the genome. Molecular mechanisms counteracting the accumulation of deleterious mutations must be important for asexual relatives to persist in the long-term. However, in most lineages, the "Meselson effect" seems to be countered, probably because of the efficiency of DNA repair mechanisms (Martens et al. 2003; Schaefer et al. 2006; Schön and Martens 2003).

In sexual organisms, gamete dimorphism is considered as an adaptation that increases gamete encounter rates and recombination opportunities (Czárán and Hoesktra 2004). Nevertheless, anisogamy also introduces the sexual conflict (Rice 2000; Bjork and Pitnik 2006), which in turn, could favor a reversal towards asexuality (Lodé 2011). Hybrid lineages could therefore be affected by genetic factors selecting for asexuality but they could also find some favorable survival aptitude under certain environmental conditions. Because they possess both biological 370 traits of their two parents, the resulting single cross hybrids are supposed to display 371 intermediate phenotypes. A hypothesis, known as "the general purpose genotype model" (Baker 372 and Stebbins 1965), argues that hybrids could be generalists. Their broad tolerance range could 373 be favorable for the evolution of clones in temporary changing conditions (Schultz 1971; Lynch 374 1984). The hybrid's genotype fits a broad ecological niche so it should exhibit a similar fitness 375 level in both parental and intermediate niches. In hemiclonal water frog, some empirical 376 evidence may be consistent with a generalist use of habitats but data are not univocal (Pagano 377 et al. 2008 for instance). Rather than showing a generalist strategy, numerous parthenogenetic 378 species adopt more or less specialized ecological niches, and numerous empirical observations 379 do not support the "general purpose genotype" hypothesis (Robinson et al. 2002; Vorburger et 
al. 2003; Pagano et al. 2008). As a result, asexual hybrids can hardly compete with parental species in selective environments; therefore their lineages should decline in the long-term.

383 Alternatively, hybrids could exploit a different restricted range of resources along the 384 environmental gradient, and hence, only occupy a narrow ecological niche, following the model 385 developed by Vrijenhoek $(1994 ; 1998)$ on hybrid zones. The "frozen niche variation" model 386 predicts that hybrids could benefit by occupying niches that differ from their parental species and cannot be used (frozen niche, Fig. 2.). Thus, it could be proposed that, rather than being generalists, parthenogenetic hybrid lineages could be favored when exploiting peculiar restricted ecological niches. Indeed, an "asexual" hybrid progeny may extend part of the ecological valence of their sexual parental species by experiencing different ecological conditions. Although hybridization events have resulted in sex loss, probably due to 392 intragenomic conflict, "asexual" hybrids are likely to show new selective traits. These original adaptive traits and the rapid colonization of new and sometimes extreme environments through asexual reproduction could favor the maintenance of these asexual lineages, and even lead to hybrid speciation (Seehausen 2004; Mallet 2007; Rieseberg and Willis 2007).

\section{Conclusion}

Hybridization seems to have a key role in the origins of asexual eukaryotes. In any case, it seems that, rather than providing an evolutionary benefit, "asexual reproduction" in eukaryotes is influenced by processes involving genomic conflict, thus leading some species to abandon a former sexual reproductive mechanism. The existence and the origin of "asexual" eukaryotes 404 that have lost meiotic sex therefore greatly differ from the primitive absence of sex in 405 prokaryotes. While the fragmentary and the total genetic recombination were put in place very early in evolution, meiosis, gametogenesis and syngamy appear as three fundamental

407 characteristics of eukaryotes. Sexual specific traits evolved to attract the opposite sex and thereby favor reproduction. 
410 Sexual reproduction is the basic characteristic promoting the fundamental divergence between 411 eukaryotes and prokaryotes (Lodé 2011, Lodé 2012c). Thus, it could be hypothesized that sex 412 (i.e. total recombination, meiosis, gametogenesis and syngamy) would be a driving force for 413 eukaryote evolution.

Little is known about the determinants of parthenogenesis. Parthenogenetic species often exhibit all the characteristics of anisogamy. In numerous plants, apomixy occurs with a meiosis in which one division is suppressed. It has been proposed that the reversal of sexuality is only controlled by a single dominant locus (Dujardin and Hanna 1989; Lattorff et al. 2005) entailing the suppression of recombination. Sex-determining mechanisms are however very diverse, even including environmental cues (Marin \& Backer 1998, Crews \& Bull 2009), and even species without sex chromosomes could develop into males or females and behave in a gamete-appropriate manner (Woolley et al. 2004).

Eukaryotic species with "asexual" reproduction probably derive from hybridization events between sexual species. These hybridization events have triggered an evolutionary loss of sex through genome conflict and meiotic drive but it is probable that numerous species may have kept the potential to reproduce by sexual means. The presence of male darwinulids calls into question the hypothesis that "asexual" eukaryotes are ancient asexual groups that have reproduced without sex for over 200 million years (Smith et al. 2006). As a result, that reproduction in numerous eukaryotes is obligate and primitively "asexual" cannot be known for certain. Even if they are not facultatively sexual, eukaryotic organisms should be considered as a continuum of organisms that are more or less capable (and sometimes incapable) of sexual reproduction.

Mechanisms of hybridization and horizontal gene transfers occurred in evolutionary processes and it is assumed that, mainly in primitive prokaryotes, horizontal transfers play an important

437 role in speciation (Lawrence 1999; Parnell et al. 2010; Martin, 2011; Arnold 1996). These 
438

439

440

441

442

443

444

445

446

447

448

449

450

451

452

453

454

455

456

457

458

459

460

461

462

463

464

events may also produce a reticulate evolution in eukaryotes (Matheos and Vrijenhoek 2007;

Christin et al. 2012; Genner and Turner 2012; Gilbert et al. 2012). Hybridization events seem sufficient to disrupt such a delicate mechanism as sexual meiosis and could affect sexual reproduction at a higher level than the cellular level, like the specific mate recognition system, often allowing the cost of males to be avoided.

Because asexual reproduction is supposed to be deleterious in the long run (Keightley and Eyre-Walker 2000; Arkhipova and Meselson 2004), the survival of these "asexual" eukaryotes however addresses critical evolutionary issues. Most studies dealing with asexual lineages focused on their potential evolutionary disadvantages, mainly supporting the idea that deleterious mutation accumulation should shorten their life span (Henry et al. 2012). However, examination of the evolutionary history of asexual lineages reveals that evolutionary processes act through transitional stages in which even very small temporary benefits may be enough to counter the expected selective disadvantages. Here, I emphasize that, although asexual eukaryotes are thought to be penalized by genetic incompatibilities, they may display evolutionary advantages such as local adaptations, following the "frozen niche variation" model. Thus, although hybrid events result in sex loss, probably caused by genomic conflict, asexual hybrids could have new adaptive traits and the rapid colonization of new environments through clonal reproduction could favor their long-term survival. Therefore, asexuality may have evolved as a reproductive mechanism for reducing conflict within organisms.

New avenues of research should detail the molecular basis of asexuality and should specify the phylogenetic origin of different groups in order to clarify what asexual eukaryotes have in common. Tests are now available to look for genetic signatures for meiosis or for asexual reproduction (Normark et al. 2003; Schurko and Logsdon 2008). Such works should allow a better understanding of eukaryotic specificities to be developed. 
I would like to thank David Crews and two anonymous referees for helpful suggestions.

468

469

470

471

472

473

474

475

476

477

478

479

480

481

482

483

484

485

486

487

488

489

490

491

\section{References}

Agrawal, A. F. (2009). Differences between selection on sex versus recombination in red queen models with diploid hosts. Evolution, 63, 2131-2141.

Angers, B., \& Schlosser, I. J. (2007). The origin of Phoxinus eos-neogaeus unisexual hybrids. Molecular Ecology, 16, 4562-4571.

Arkhipova, I., \& Meselson, M. (2004). Deleterious transposable elements and the extinction of asexuals. Bioessays, 27, 76-85.

Arnold, M. L. (1996). Natural Hybridization and Evolution. New York: Oxford University Press.

Baker, H. G., \& Stebbins, G. I. (1965). The genetics of colonizing species. New York: Academic Press.

Barraclough, T. G., Birky, Jr. C. W., \& Burt, A. (2003). Diversification in sexual and asexual organisms. Evolution, 57, 2166-2172.

Barton, N. H., \& Charlesworth, B. (1998). Why Sex and Recombination? Science, 281, 19861990.

Bell, G. (1993). The sexual nature of eukaryote genomes. Journal of Heredity, 84, 351-359.

Bernstein, H., Byerly, H. C., Hopf, F. A., \& Michod, R. E. (1984). Origin of sex. Journal of Theoretical of Biology, 110, 323-351.

Beukeboom, L., \& Vrijenhoek, R. C. (1998). Evolutionary genetics and ecology of spermdependent parthenogenesis. Journal of Evolutionary Biology, 11, 755-782.

Birky, W. C., Jr. (2004). Bdelloid rotifer revisited. Proceedings of the National Academy of Sciences USA, 101, 2651-2652.

Bjork, A., \& Pitnik, S. (2006). Intensity of sexual selection along the anisogamy-isogamy continuum. Nature, 441, 742-745. 
492

493

494

495

496

497

498

499

500

501

502

503

504

505

506

507

508

509

510

511

512

513

514

515

516

517

518

519

Brown, S. G., Kwan S., \& Shero, S. (1995). The parasitic theory of sexual reproduction, parasitism in unisexual and bisexual geckos. Proceedings of the Royal Society of London B, 260, 317-320.

Bruvo, R., Adolfsson S., Symonova R., Lamatsch D. K., Schön I., Jokela J., et al. (2011). Few parasites, and no evidence for Wolbachia infections in a freshwater ostracod inhabiting temporary ponds. Biological Journal of the Linnaean Society of London, 102, 208-216.

Butlin, R. (2002). The costs and benefits of sex, new insights from old asexual lineages. Nature Reviews of Genetics, 3, 311-317.

Butlin, R. K., \& Griffiths, H. I. (1993). Ageing without sex? Nature, 364, 680.

Carman, J. G. (1997). Asynchronous expression of duplicate genes in angiosperms may cause apomixis, bispory, tetraspory, and polyembryony. Biological Journal of the Linnaean Society of London, 61, 51-94.

Carman, J. G. (2007). Do duplicate genes cause apomixes? In E. Hörandl, U. Grossniklaus, P. J. van Dijk \& T. F. Sharbel (Eds.), Apomixis, Evolution, mechanisms and perspectives (pp. 6391). Liechtenstein: Gantner Rugell.

Cavalier-Smith, T. (2002). Origins of the machinery of recombination and sex. Heredity, 8, 125141.

Chaplin, J. A., Havel, J. E., \& Hebert, P. D. N. (1994). Sex and ostracods. Trends in Ecology and Evolution, 9, 435-439.

Christin, P. A., Edwards, E. J., Besnard, G., Boxall, S. F., Gregory, R., Kellogg, E. A., et al. (2012). Adaptive evolution of C4 Photosynthesis through recurrent lateral gene transfer. Current Biology, 22, 445-449.

Clay, K., \& Kover, P. X. (1996). The Red Queen Hypothesis and plant/pathogen interactions. Annuals Reviews of Phytopathology, 34, 29-50.

16 Cooper, T. F. (2007). Recombination speeds adaptation by reducing competition between 17 beneficial mutations in populations of Escherichia coli. PLoS Biology, 59, e225.

18 Coyne, J. A., \& Orr, H. A. (1993). Further evidence against meiotic-drive models of hybrid 19 sterility. Evolution, 47, 685-687. 
520 Crews, D., Grassman, M., \& Lindzey J. (1986). Behavioral facilitation of reproduction in sexual 521 and unisexual whiptail lizards, Proc Natl Acad Sci USA, 83, 9547-9550.

522 Crews, D. (2012). The (bi)sexual brain. Embo reports (in press).

523 Crews, D., \& Bull J. J. (2009). Mode and tempo in environmental sex determination in 524 vertebrates. Seminar Cell Development Biology, 20, 251-255.

525 Cullum, A. (2000). Phenotypic variability of physiological traits in populations of sexual and 526 asexual whiptail lizards (genus Cnemidophorus). Evolutionary Ecology Research, 2, 841-855.

527 Czárán, T. L., \& Hoesktra, R. F. (2004). Evolution of sexual asymmetry. BMC Evolutionary 528 Biology, 4, 34.

529 de Queiroz, K. (2005). Ernst Mayr and the modern concept of species. Proceedings of the $530 \quad$ National Academy of Sciences USA, 102, 6600-6607.

531 de Visser, J. A. G. M., \& Elena, S. F. (2007). The evolution of sex, Empirical insights into the 532 roles of epistasis and drift. Nature Reviews of Genetics, 8, 139-149.

533 Domes, K., Norton, R. A., Maraun, M., \& Scheu, S. (2007). Revolution of sexuality breaks 534 Dollo's law. Proceedings of the National Academy of Sciences USA, 104, 7139-7144.

535 Dujardin, M., \& Hanna, W. W. (1989). Developing apomictic pearl millet characterization of a 536 BC3 plant. Journal of Genetic Breeding, 43, 145-151.

537 Dunthorn, M., \& Katz, L. (2010). Secretive ciliates and putative asexuality in microbial 538 eukaryotes. Trends in Microbiology, 18, 183-188.

539 Dyer, P. S., \& Paoletti, M. (2005). Reproduction in Aspergillus fumigatus, sexuality in a 540 supposedly asexual species? Medical Mycology Supplement, 43, S7-S14.

541 Egel, R. (2000). Fission yeast on the brink of meiosis. BioEssays, 22, 854-860.

542 Felsenstein, J. (1974). The evolutionary advantage of recombination. Genetics, 78, 737-756.

543 Fontaneto, D., Herniou, E. A., Boschetti, C., Caprioli, M., Melone, G., Ricci, C., et al. (2007).

544 Independently evolving species in asexual bdelloid rotifers. Plos Biology, 5, e87.

545 Genner, M. J., \& Turner, G. F. (2012). Ancient hybridization and phenotypic novelty within Lake 546 Malawi's Cichlid fish radiation. Molecular Biology and Evolution, 29, 195-206. 
547 Ghiselli, F., Milani, L., Scali, V., \& Passamonti, M. (2007). The Leptynia hispanica species

548 complex (Insecta Phasmida), polyploidy, parthenogenesis, hybridization and more. Molecular 549 Ecology, 16, 4256-4268.

550 Gilbert, C., Hernandez, S. S., Flores-Benabib, J., Smith, E. N., \& Feschotte, C. (2012). Rampant

551 horizontal transfer of SPIN transposons in Squamate Reptiles. Molecular Biology and

552 Evolution, 29, 503-515.

553 Goddard, M. R., Godfray, H. C. J., \& Burt, A. (2005). Sex increases the efficacy of natural 554 selection in experimental yeast populations. Nature, 434, 636-640.

555 Goldberg, E. E. \& Igic, B. (2008). On phylogenetic tests of irreversible evolution. Evolution, 62, $556 \quad 2727-2741$.

557 Guillon, J.M. \& Raquin, C. (2002) Environmental sex determination in the genus Equisetum :

558 sugars induce male sex expression in cultured gametophytes. International Journal of Plant 559 Science, 163, 825-830.

560 Haag, C. R., Sakwinska, O. \& Ebert, D. (2003). Test of synergistic interactions between 561 infection and inbreeding in Daphnia magna. Evolution, 57, 777-783.

562 Hadany, L. \& Feldman, M. W. (2005). Evolutionary traction, the cost of adaptation and the 563 evolution of sex. Journal of Evolutionary Biology, 18, 309-314.

564 Hakoyama, H., Nishimura, T., Matsubara, N., \& Iguchi, K. (2001). Difference in parasite load 565 and nonspecific immune reaction between sexual and gynogenetic forms of Carassius auratus. 566 Biological Journal of the Linnaean Society of London, 72, 401-407.

567 Haldane, J. B. S. (1922). Sex ratio and unisexual sterility in hybrid animals. Journal of Genetics, 568 12, 101-109.

569 Halkett, F., Simon, J.-C., \& Balloux, F. (2005). Tackling the population genetics of clonal and 570 partially clonal organisms. Trends in Ecology and Evolution, 20, 194-201.

571 Hamilton, W. D. (1980). Sex versus non-sex versus parasite. Oikos, 35, 282-290.

572 Hamilton, W. D., Axelrod, R., \& Tanese, R. (1990). Sexual reproduction as an adaptation to 573 resist parasites (a review). Proceedings of the National Academy of Sciences USA, 87, 35665743573. 
575 Hanley, K. A., Fisher, R. N., \& Case, T. J. (1995). Lower mite infestations in an asexual gecko 576 compared with its sexual ancestors. Evolution, 49, 418-426.

577 Heethoff, M., Domes, K., Laumann, M., Maraun, M., Norton, R. A., \& Scheu, S. (2007). High 578 genetic divergences indicate ancient separation of parthenogenetic lineages of the oribatid mite 579 Platynothrus peltifer (Acari, Oribatida). Journal of Evolutionary Biology, 20, 392-402.

580 Henry, L., Schwander, T., \& Crespi, B. J. (2012). Deleterious mutation accumulation in asexual 581 Timema stick insects. Molecular Biology and Evolution, 29, 401-408.

582 Hillis, D. M. (2007). Asexual evolution, can species exist without sex? Current Biology, 17, 583 R543-R544.

584 Hörandl, E., Cosendai, A.-C., \& Temsch, E. (2008). Understanding the geographic distributions 585 of apomictic plants, a case for a pluralistic approach. Plant Ecology and Diversity, 2, 309-320 586 Howard, R. S. \& Lively, C. M. (1994). Parasitism, mutation accumulation and the maintenance 587 of sex. Nature, $367,554-557$.

588 Johnson, S. J. (2000). Populations structure, parasitism and survivorship of sexual and asexual 589 autodiploid parthenogenetic Campeloma limum. Evolution, 54, 167-175.

590 Judson, O. P., \& Normark, B. B. (1996). Ancient asexual scandals. Trends in Ecology and 591 Evolution, 11, A41-A46.

592 Kearney, M. (2005). Hybridization, glaciation and geographical parthenogenesis. Trends in 593 Ecology and Evolution, 20, 495.

594 Kearney, M., \& Shine, R. (2005). Lower fecundity in parthenogenetic geckos than sexual 595 relatives in the Australian arid zone. Journal of Evolutionary Biology, 18, 609-618.

596 Keightley, P. D., \& Eyre-Walker, A. (2000). Deleterious mutations and the evolution of sex. 597 Science, 290, 331-333.

598 Kondrashov, A. S. (1993). Classification of hypotheses on the advantage of amphimixis. Journal 599 of Heredity, 84, 372-387.

600 Kondrashov, A. S. (1994). The asexual ploidy cycle and the origin of sex. Nature, 370, 213-216. 601 Ladle, R. J. (1992). Parasites and sex, catching the red queen. Trends in Ecology and 602 Evolution, 7, 405-408. 
603

604

605

606

607

608

609

610

611

612

613

614

615

616

617

618

619

620

621

622

623

624

625

626

627

628

629

630

Lamatsch, D. K., Lampert, K. P., Fischer, P., Epplen, J. T., Nanda, I., Schmid, M., et al. (2007).

Automictic reproduction in interspecific hybrids of poeciliid fish. Current Biology, 17, 1948-1953.

Lattorff, H. M. G., Moritz, R. F. A., \& Fuchs, S. (2005). A single locus determines thelytokous parthenogenesis of laying honeybee workers (Apis mellifera capensis). Heredity, 94, 533-537.

Lawrence, J. G. (1999). Gene transfer, speciation, and the evolution of bacterial genomes.

Current Opinion Microbiology, 2, 519-523.

Lesbarrères, D. (2011). Sex or no sex, reproduction is not the question. BioEssays, 33, 818.

Lively, C. M. \& Lloyd, D. G. (1990). The cost of biparental sex under individual selection.

American Naturalist, 135, 489-500.

Lively, C. M. (2009). The maintenance of sex, host-parasite coevolution with density-dependent virulence. Journal of Evolutionary Biology, 22, 2086-2093.

Lively, C. M., \& Jokela, J. (2002). Temporal and spatial distributions of parasites and sex in a freshwater snail. Evolutionary Ecological Research, 4, 219-226

Lively, C. M., Craddock, C., \& Vrijenhoek, R. C. (1990). Red queen hypothesis supported by parasitism in sexual and clonal fish. Nature, 344, 864-867.

Lodé, T. (2011). Sex is not a solution for reproduction, the libertine bubble theory. BioEssays, 33, 419-422.

Lodé, T. (2012a). Sex and the origin of genetic exchanges. Trends in Evolutionary Biology, 2012, 4 e1.

Lodé, T. (2012b). For quite a few chromosomes more: the origin of eukaryotes. Journal of Molecular Biology, 423, 135-142.

Lodé, T. (2012c). Have sex or not? Lessons from bacteria. Sexual Development, 6, 325-328.

Loxdale, H. D., \& Lushai, G. (2003). Rapid changes in clonal lines, the death of a 'sacred cow. Biological Journal of the Linnaean Society, 79, 3-16.

Lunt, D. H. (2008). Genetic tests of ancient asexuality in root knot nematodes reveal 536 recent hybrid origins. BMC Evolutionary Biology, 8, 194.

Lushai, G., Loxdale, H. D., \& Allen, J. A. (2003). The dynamic clonal genome and its adaptive potential. Biological Journal of the Linnaean Society of London, 79, 193-208. 
631 Lynch, M. (1984). Destabilizing hybridization, general-purpose genotypes, and geographic

632 parthenogenesis. Quaternary Review of Biology, 59, 257-290.

633 Mable, K. (2007). Sex in the postgenomic era. Trends in Ecology and Evolution, 2, 559-561.

634 Mallet, J. (2007). Hybrid speciation. Nature, 446, 279-283.

635 Marin, I., \& Baker, B. S. (1998) The evolutionary dynamics of sex determination. Science, 281, $636 \quad 1990-1994$.

637 Mark-Welch, D., \& Meselson, M. (2000). Evidence for the evolution of bdelloid rotifers without 638 sexual reproduction or genetic exchange. Science, 288, 1211-1215.

639 Mark-Welch, J. L., Mark-Welch, D. B., \& Meselson, M. (2004). Cytogenetic evidence for asexual 640 evolution of bdelloid rotifers. ? Proceedings of the National Academy of Sciences USA, 101, $641 \quad 1618-1621$.

642 Martens, K., Rossetti, G., \& Home, D. J. (2003). How ancient are ancient asexuals?

643 Proceedings of the National Academy of Sciences USA, 270, 723-729.

644 Martin, W. F. (2011). Early evolution without a tree of life. Biology Direct, 6, 36.

645 Matheos, M., \& Vrijenhoek, R. C. (2007). Ancient versus reticulate origin of hemiclonal lineage. 646 Evolution, 56, 985-992.

647 Maynard-Smith, J. (1978). The evolution of sex. Cambridge University Press, Cambridge, UK.

648 McDaniel, L. D., Young, E., Delaney, J., Ruhnau, F., Ritchie, K. B., \& Paul, J. H. (2010). High 649 frequency of horizontal gene transfer in the oceans. Science, 330, 50.

650 McDermott, S. R., \& Noor, M. A. F. (2010). The role of meiotic drive in hybrid male sterility. 651 Philosophical Transactions of the Royal Society B, 365, 1265-1272.

652 Morran, L. T., Schmidt, O. G., Gelarden, I. A., Parrish II, R. C., \& Lively, C. M. (2011). Running 653 with the red queen, host-parasite coevolution selects for biparental sex. Science, 333, 216-218. 654 Muller, H. J. 1964. The relation of mutation to mutational advance. Mutation Research, 1, 2-9. 655 Normark, B. B., Judson, O. P., \& Moran, N. A. (2003). Genomic signatures of ancient asexual 656 lineages. Biological Journal of the Linnaean Society of London, 79, 69-84.

657 Nygren, A., \& Sundberg, P. (2003). Phylogeny and evolution of reproductive modes in 658 Autolytinae Syllidae, Annelida. Molecular Phylogeny and Evolution, 29, 235-249. 
659 Ochman, H., Lerat, E., \& Daubin, V. (2005). Examining bacterial species under the specter of 660 gene transfer and exchange. Proceedings of the National Academy of Sciences USA, 102, $661 \quad 6595-6599$.

662 Otto, S. P. (2009). The evolutionary enigma of sex. American Naturalist, 174, S1-14.

663 Pagano, A., Lesbarrères, D., O'hara, R., Crivelli, A., Veith, M., Lodé, T., \& Schmeller, D. S.

664 (2008). Geographical and ecological distributions of frog hemiclones suggest occurrence of both 665 "General Purpose Genotype" and "Frozen Niche Variation" clones. Journal of Zoological 666 Systems in Evolutionary Research, 46, 162-168.

667 Pagano, A., Dubois, A., Lesbarrères, D., \& Lodé, T. (2003). Frog alien species, a way for 668 genetic invasion? Comptes-Rendus Biologies, 326, 85-92

669 Pal, C., Macia, M., Oliver, A., Schacher, I., \& Buckling, A. (2007). Coevolution with viruses 670 drives the evolution of bacterial mutation rates. Nature, 450, 1079-1081.

671 Parker, Jr E. D., \& Selander, R. K. (1976). The organization of genetic diversity in the 672 parthenogenetic lizard Cnemidophorus tesselatus. Genetics, 84, 791-805.

673 Parnell, J. J., Rompato, G., Latta IV, L. C., Pfrender, M. E., Van Nostrand, J. D., He, Z., Zhou, 674 J., Andersen, G., Champine, P., Balasubramanian, G., \& Weimer, B. C. (2010). Functional 675 biogeography as evidence of gene transfer in hypersaline microbial communities. PLoS One, 5, 676 e12919. doi,10.1371/journal.pone.0012919

677 Passamonti, M., Mantovani, B., \& Scali, V. (2004). Phylogeny and karyotype evolution of the 678 Iberian Leptynia attenuata species complex (Insecta Phasmatodea). Molecular Phylogeny and 679 Evolution, 30, 87-96.

680 Penny, D. (1985). The evolution of meiosis and sexual reproduction. Biological Journal of the 681 Linnaean Society of London, 25, 209-220.

682 Phadnis, N., \& Orr, H. A. (2009). A single gene causes both male sterility and segregation 683 distortion in Drosophila hybrids. Science, 323, 376-379.

684 Presgraves, D. C. (2007). Speciation genetics, epistasis, conflict and the origin of species. 685 Current Biology, 17, R125-R127. 
686 Quarin, C. L., Espinoza, F., Martinez, E. J., Pessino, S. C., \& Bovo, O. A. (2001). A rise of ploidy

687 level induces the expression of apomixis in Paspalum notatum. Sex Plant Reproduction, 13, $688 \quad 243-249$

689 Ramesh, M. A., Malik, S., \& Logsdon, J. M. (2005). A phylogenomic inventory of meiotic genes, 690 evidence for sex in Giardia and an early eukaryotic origin of meiosis. Current Biology, 15, 185691191.

692 Redfield, R. (2001). Do bacteria have sex? Nature Reviews of Genetics, 2, 634-639.

693 Rice, W. R. (2000). Dangerous liaisons. Proceedings of the National Academy of Sciences 694 USA, 97, 12953-12955.

695 Rice, W. R. (2002). Experimental tests of the adaptive significance of sexual recombination. 696 Nature Reviews of Genetics, 3, 241-251.

697 Rieseberg, L., \& Willis, J. H. (2007). Plant speciation. Science, 317, 910-914.

698 Robinson, M. T., Weeks, A. R., \& Hoffmann, A. A. (2002). Geographic patterns of clonal 699 diversity in the earth mite species Penthaleus major with particular emphasis on species 700 margins. Evolution, 56, 1160-1167.

701 Salathé, P., \& Ebert, D. (2003). The effects of parasitism and inbreeding on the competitive 702 ability in Daphnia magna, evidence for synergistic epistasis. Journal of Evolutionary Biology, 16, $703 \quad 976-985$.

704 Schaefer, I., Domes, K., Heethoff, M., Schneider, K., Schön, I., Norton, R. A., et al. ( 2006). No 705 evidence for the "Meselson effect" in parthenogenetic oribatid mites (Oribatida, Acari). Journal 706 of Evolutionary Biology, 19, 184-193.

707 Schartl, M., Wilde, B., Schlupp, I., \& Parzefall, J. (1995). Evolutionary origin of a parthenoform, 708 the Amazon Molly Poecilia formosa, on the basis of a molecular genealogy. Evolution, 49, 827709835.

710 Schley, D., Doncaster, C., \& Slutkin, T. (2004). Population models of sperm-dependent 711 parthenogenesis. Journal of Theoretical Biology, 229, 559-572.

712 Schmeller, D. S., O'Hara, R., \& Kokko, H. (2005). Male adaptive stupidity, male mating pattern 713 in hybridogenetic frogs. Evolutionary Ecological Research, 7, 1039-1050 
714 Schmidt, B. R. (1993). Are hybridogenetic frogs cyclical parthenogens? Trends in Ecology and

715 Evolution, 8, 271-273.

716 Schön, I., \& Martens, K. (2003). No slave to sex. Proceedings of the Royal Society of London B, $717270,827-833$.

718 Schön, I., Butlin, R. K., Griffiths, H. I., \& Martens, K. (1998). Slow evolution in an ancient

719 asexual ostracod. Proceedings of the Royal Society of London B, 265, 235-242.

720 Schultz, R J. (1971). Special adaptive problems associated with unisexual fishes. American

721 Zoologist, 11, 351-360.

722 Schurko, A. M., \& Logsdon, Jr J. M. (2008). Using a meiosis detection toolkit to investigate 723 ancient asexual "scandals". BioEssays, 30, 579-589.

724 Schwander, T., \& Crespi, B. J. (2008). Multiple direct transitions from sexual reproduction to 725 apomictic parthenogenesis in Timema stick insects. Evolution, 63, 84-103.

726 Seehausen, O. (2004). Hybridization and adaptive radiation. Trends in Ecology and Evolution, 727 19, 198-207.

728 Simon, J. C., Delmotte, F., Rispe, C., \& Crease, T. (2003). Phylogenetic relationships between 729 parthenogens and their sexual relatives, the possible routes to parthenogenesis in animals.

730 Biological Journal of the Linnaean Society of London, 79, 151-163.

731 Slobodchikoff, C. N., \& Daly, H. V. (1971). Systematic and evolutionary implications of 732 parthenogenesis in the Hymenoptera. American Zoologist, 11, 273-282.

733 Smith, R. J., Kamiya, T., \& Horne, D. J. (2006). Living males of the 'ancient asexual'

734 Darwinulidae (Ostracoda, Crustacea). Proceedings of the National Academy of Sciences USA, $735 \quad 273,1569-1578$.

736 Sun, S., \& Heitman, J.( 2011). Is sex necessary ? BMC Biology, 9, 56.

737 Suomalainen, E. (1962). Significance of Parthenogenesis in the Evolution of Insects. Annual 738 Review of Entomology, 7, 349-366.

739 Suomalainen, E., Saura, E., \& Lokki, J. (1976). Evolution of parthenogenetic insects.

740 Evolutionary Biology, 9, 209-257.

741 Tobler, M., \& Schlupp, I. (2005). Parasites in sexual and asexual mollies Poecilia, Poeciliidae, 742 Teleostei, a case for the Red Queen? Biology Letters, 1, 166-168. 
743 Uyenoyama, M. K. (1984). On the evolution of parthenogenesis, A genetic representation of the

744 "cost of meiosis". Evolution 38, 87-102.

745 Venditti, P. C., Meade, A., \& Pagel, M. (2010). Phylogenies reveal new interpretation of

746 speciation and the Red Queen. Nature, 463, 349-352.

747 Vorburger, C. (2001). Heterozygous fitness effects of clonally transmitted genomes in

748 waterfrogs. Journal of Evolutionary Biology, 14, 602-610.

749 Vorburger, C., Sunnucks, P., \& Ward, S. A. (2003). Explaining the coexistence of asexuals with 750 their sexual progenitors, no evidence for general-purpose genotypes in obligate parthenogens

751 of the peach-potato aphid, Myzus persicae. Ecology Letters, 6, 1091-1098.

752 Vos, M. (2009). Why do bacteria engage in homologous recombination? Trends in Microbiology, $753 \quad 17,226-232$.

754 Vrijenhoek, R. C. (1994). Unisexual fish, model systems for studying ecology and evolution.

755 Annual Review of Ecological System, 25, 71-96.

756 Vrijenhoek, R. C. (1998). Animal clones and diversity. Are natural clones generalists or 757 specialists? Bioscience, 48, 617-628.

758 Watson, R. A., Weinreich, D. M. \& Wakeley, J. (2011). Genomes structure and the benefit of 759 sex. Evolution, 65, 523-536.

760 Wenseleers, T., \& Van Oystaeyen, A. (2011). Unusual modes of reproduction in social insects:

761 Shedding light on the evolutionary paradox of sex. BioEssays, 33, 927-937.

762 Wilkinson, G. S., \& Fry, C. L. (2001). Meiotic drive alters sperm competitive ability in stalk-eyed 763 flies. Proceedings of the Royal Society of London B, 268, 2559-2564.

764 Williams, G. C. (1975). Sex and evolution. Princeton: Princeton University Press.

765 Woolley S. C., Sakata J. T., \& Crews D. (2004). Tracing the Evolution of Brain and Behavior 766 Using Two Related Species of Whiptail Lizards: Cnemidophorus uniparens and Cnemidophorus 767 inornatus. ILAR Journal, 45, 46-53. 


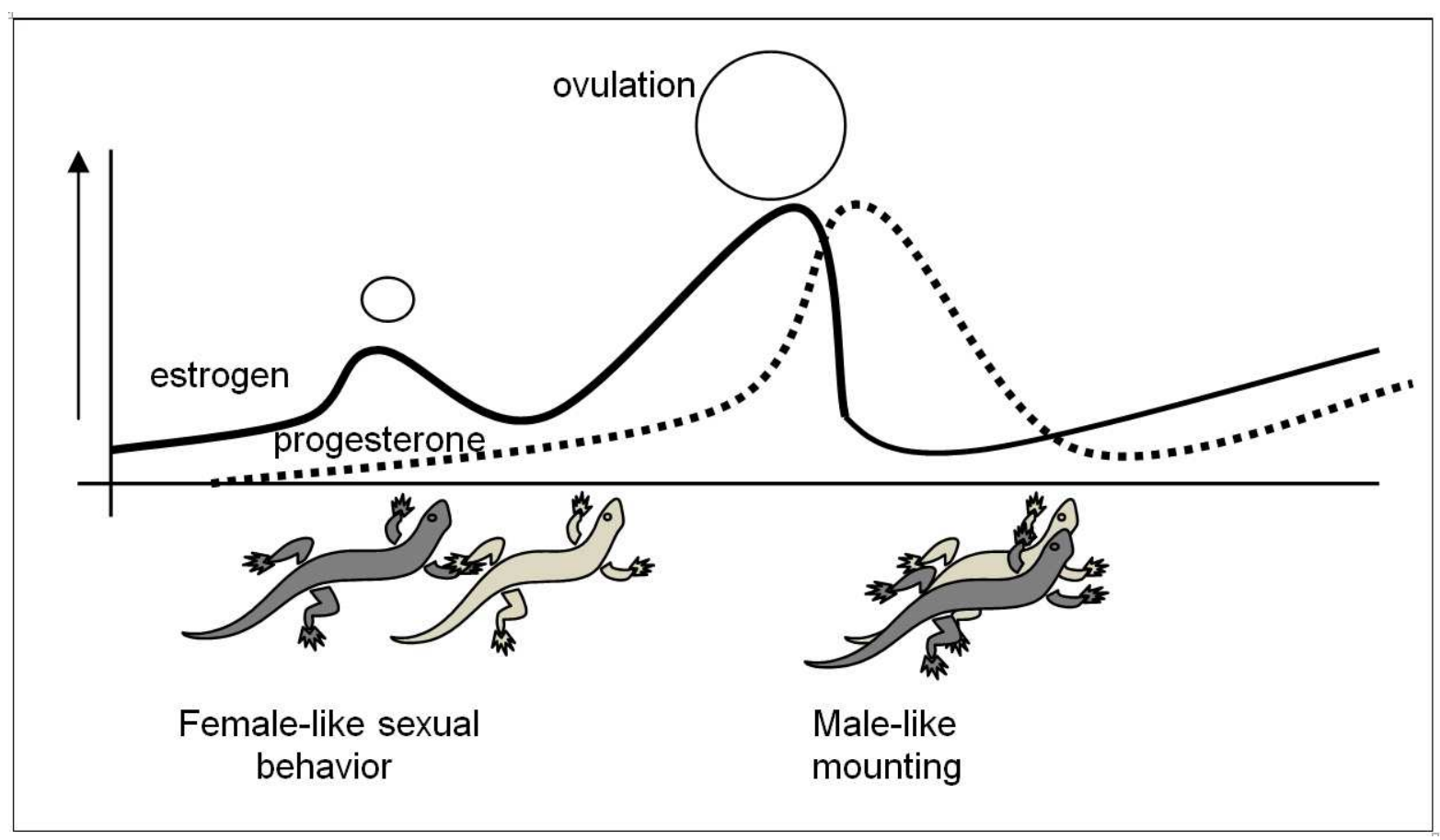

Fig. 1 Sexual behavior in the diploid parthenogenetic lizard Aspidoscelis /Cnemidophorus uniparens related to the ovarian cycle (based on Woolley et al. 2004)

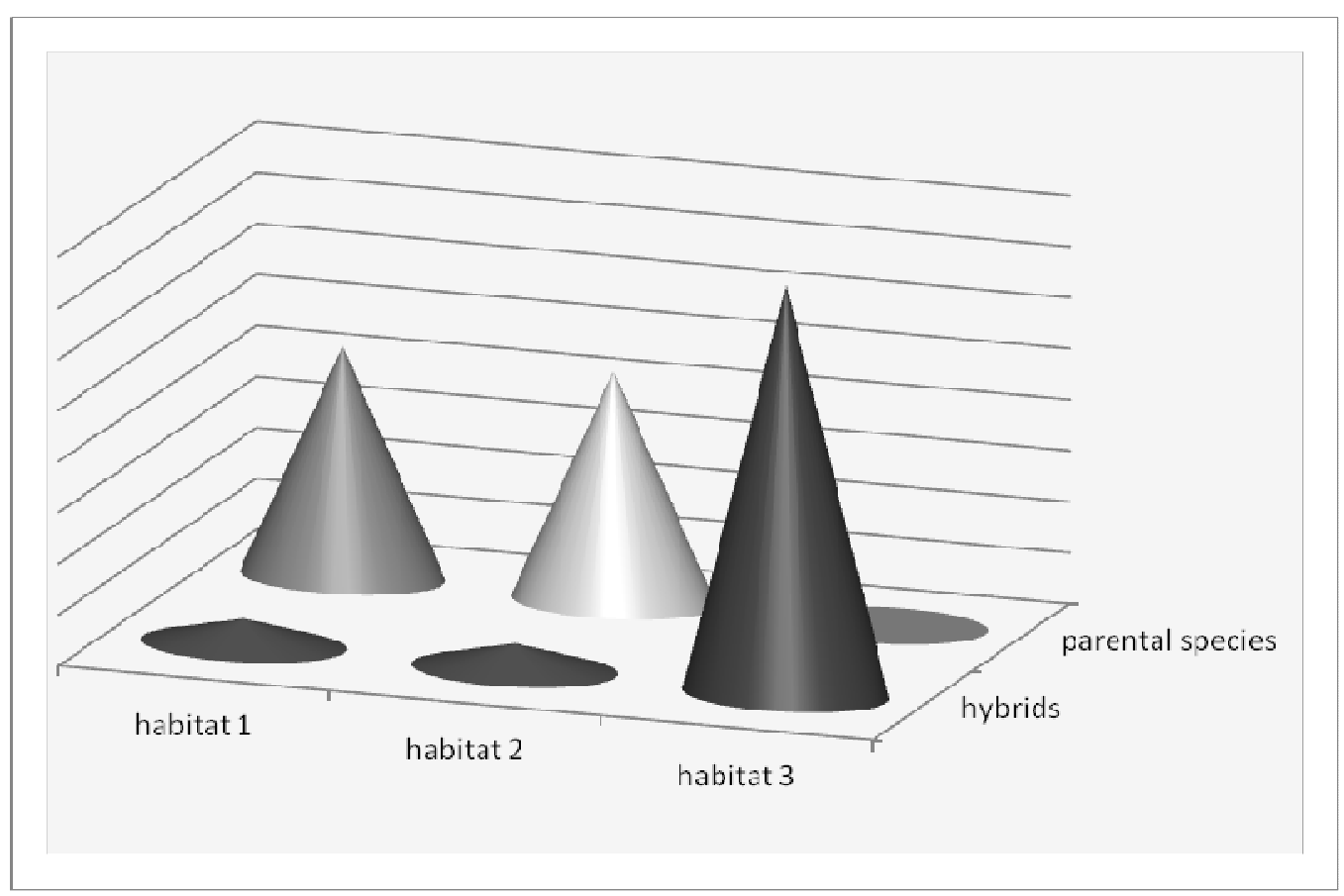

Fig. 2 "Frozen niche variation" model predicting that hybrids could benefit by occupying niches that differ from their two parental species and cannot be used leading to putative hybrid 